\title{
Interscalene block for double fracture of right hand using bupivicaine and lidocaine with dexamethasone
}

W. Kamal ${ }^{1}$, M. Golyanishev².

${ }^{1}$ Centre hospitalier Elyousef, Anesthesia, Halba. Akkar, Lebanon.

${ }^{2} \mathrm{KMAPO}$, Kharkov medical academy of postgraduate education, Kharkov, Ukraine.

Key words

Interscalene block for double fracture with bupivicaine lidocaine and dexamethasone

\section{Background and Aims:}

The analgesic effect of an interscalene block with bupivicaine and lidocaine in a mixture ratio:1:1 with dexamethasone intravenously

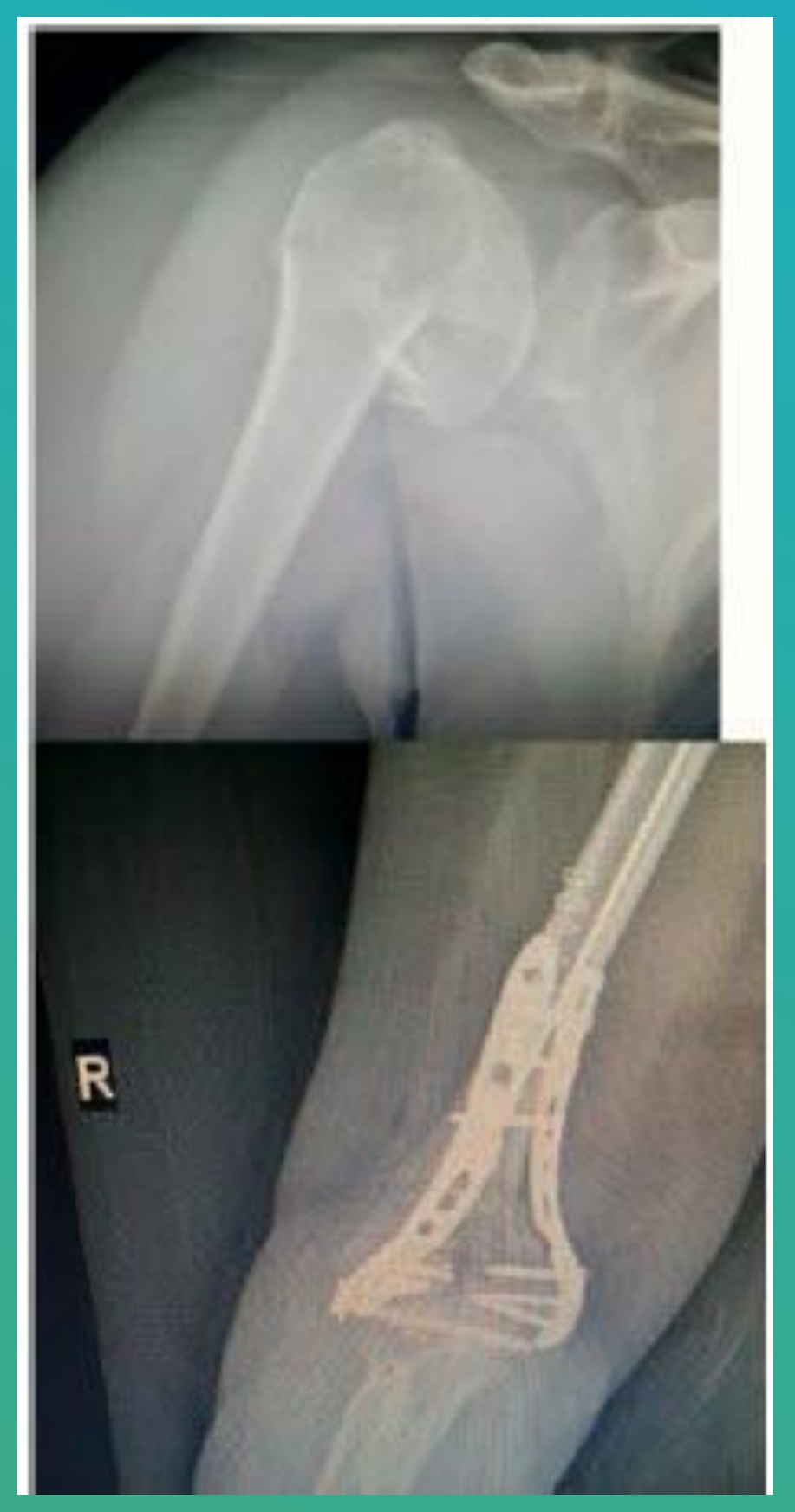

Methods:
A 68 years old female was admitted and
scheduled for an urgent operation
because she was in visit in Lebanon
and had to leave for her country.
She had a double fracture in the right
upper limb: clavicular and elbow
fractures.
An interscalene block was done using
bupivicaine $0.5 \%-20 \mathrm{ml}$ and lidocaine
$2 \%-20 \mathrm{ml}$ in 2 syringe of $20 \mathrm{ml}$ mixed
together then $8 \mathrm{mg}$ of dexamethasone
was given intravenously.
After the settling of the block the patient
was intubated given $2 \mathrm{mg}$ of midazolam
$50 \mathrm{mcg}$ of fentanyl $100 \mathrm{mg}$ of propofol
and $8 \mathrm{mg}$ of nimbex. Patient was in back
rest position and the maintenance was
by sevoflurane

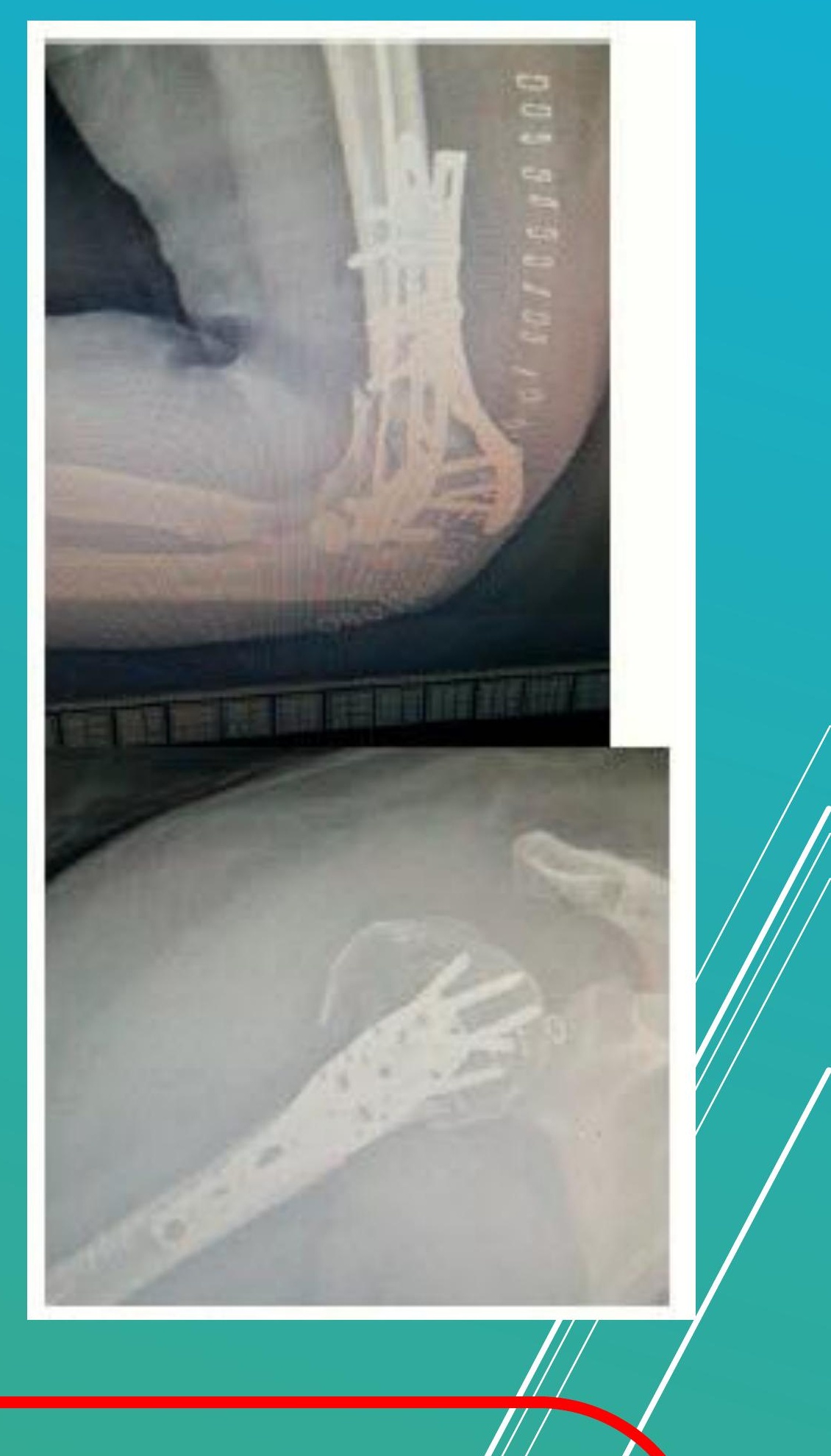

\section{Results}

The operation took 6 hours. The blood pressure was between 95 and $85 \mathrm{~mm} \mathrm{hg}$ for the systolic and 65 to $50 \mathrm{~mm}$ hg for the diastolic the heart rate was between 62 and 65 beat by min. No fentanyl was added. After the extubation the patient was in the recovery room for 30 min then sending her to the wards. She didn't take any analgesia in the recovery room the EVA was $<40$. After 4 hours she didn't need any analgesia and after 3 hours she went home without no pain.

\section{Conclusions:}

An ISB with bupivicaine and lidocaine in a mixture of $1: 1$ with $8 \mathrm{mg}$ of dexamethasone iv gives a good analgesic effect more then 8 hours 